\title{
Measuring light in field experiments using dummies and objects: A study of concert lighting
}

VWL Lo PhD, RIBA and KA Steemers PhD, RIBA

Department of Architecture, The Martin Centre for Architectural and Urban

Studies, University of Cambridge, Cambridge, UK

Short title: Measuring light in field experiments

Received 29 November 2016; Revised 22 December 2017; Accepted 10 January 2018

Lighting experiments were performed in a real context populated with dummies and objects. Using the King's College Chapel in Cambridge as a case study, two field surveys of concert lighting were performed, one with the chapel empty and one with it occupied. In each survey, photometric data were collected under three electric lighting conditions and from six different viewing positions. A comparative analysis indicates that the data gathered from the occupied space represent the luminances more accurately, present a more detailed description of the light distribution, and provide a more extensive set of variables characterising the geometrical details of the visual scene. This study demonstrates the importance of using occupied spaces and considering the presence of occupants in field studies, which could be useful for obtaining a more complete understanding of complex luminous environments.

Address for correspondence:

VWL Lo, Department of Architecture, The Martin Centre for Architectural and Urban Studies, University of Cambridge, 1-5 Scroope Terrace, Cambridge CB2 1PX, UK. Email: villianlo@cantab.net 


\section{Introduction}

Lighting research has focused on occupancy when designing control systems (usually in pursuit of energy efficiency), ${ }^{1,2}$ on the effects of light on people's visual comfort and health, ${ }^{3-6}$ and on how light influences people's appearance (often in the context of face recognition) ${ }^{7,8}$ Room contents - physical objects - and their effects on light fields have been widely studied, ${ }^{9}$ but rarely are occupants and their relationship with the surroundings considered collectively as part of the determinants of lighting conditions. Unlike using objects in lighting studies, the inclusion of real people as part of a lit scene is not as straightforward as it first seems and such an approach could raise fundamental issues concerning logistics, practical limitations and ethics. A widely-recognised weakness in many lighting studies ${ }^{4,10-15}$ has been that they were performed in a tightly-controlled laboratory environment, in empty space, in a virtual environment or with scale models. In only a few studies have people been included in the analysis. ${ }^{16-19}$ Nonetheless, the built environment is complex. A simplified room or context with just a few occupants is not sufficient to represent what we see and experience in reality. Most fundamentally, if we fail to study a reasonably realistic occupied lit environment, how can specific effects and impressions created by illumination be induced for further investigation?

During the 1960s and 1970s, studies by Hewitt et al. ${ }^{16}$ and by Kimmel and Blasdel ${ }^{20}$ used real settings to investigate lighting factors which influence the impressions of a luminous environment. These were early attempts to respond to calls for such research by the Commission Internationale de l'Eclairage (CIE) and the Illuminating Engineering Society. ${ }^{16,21,22}$ However, the complexity of typical visual scenes and the lack of a standardised and robust experimental procedure for evaluating lighting quality led to 
inconclusive findings. This prompted the lighting community to initiate a series of further laboratory studies.

Table 1 summarises the experimental settings and visual foci of some oft-cited studies, as well as others that shared similar research objectives. Most were conducted in unoccupied spaces, either in a laboratory or in a real setting. They yielded mixed results. Here are some of the key observations:

- By instructing research subjects to make comparative judgements of six different light settings in a tightly-controlled conference room with minimal furniture, Flynn's et al. ${ }^{23,24}$ observed that similar luminous appearances and characteristics may provide the same specific visual signals and cues, and may therefore stimulate similar lighting perceptions. Contradicting these findings, Hawkes et al. ${ }^{25}$ who conducted similar experiments in a windowless office with 18 light settings, found no definite correlation patterns relating visual interest with light measures.

- Extending the scope of that research, Loe et al. ${ }^{26,27}$ replicated the Hawkes et al. experiment in a mock-up of a conference room with 18 different lighting configurations. They observed that a minimum average luminance of $30 \mathrm{cdm}^{-2}$ and a uniformity ratio of 13:1 provided a bright, interesting and acceptable visual appearance. But contrary to those findings, groups led by Rothwell and Campbel128 and Perry et al. ${ }^{29}$ observed that subjects are likely to experience gloominess when the average luminance falls below $120 \mathrm{cdm}^{-2}$. Their findings were based on a series of experiments using generic visual tasks.

- Moore et al., ${ }^{30-32}$ among others, conducted task-based assessments in real office settings. They reported that an average luminance of $20 \mathrm{cdm}^{-2}$ is considered highly 
satisfactory, which is $10 \mathrm{cdm}^{-2}$ less than the Loe et al. recommendation and 100 $\mathrm{cdm}^{-2}$ lower than those of Rothwell and Campbell and of Perry et al. Using real settings could have led to the discrepancies because of the more complex spatial geometries and content of the visual scene, including windows (daylight entering and views out) and the presence of moving, interacting workers. 
Table 1. The visual foci in oft-cited research studies

\begin{tabular}{|c|c|c|c|c|c|c|c|c|c|}
\hline \multirow[b]{2}{*}{ Study } & \multirow[b]{2}{*}{ Setting } & \multicolumn{8}{|c|}{ Visual focus } \\
\hline & & $\begin{array}{l}\frac{\mathscr{a}}{\pi} \\
\frac{\pi}{2} \\
\frac{0}{0} \\
3\end{array}$ & $\frac{\dot{0}}{\bar{I}}$ & $\overline{\bar{\pi}}$ & $\frac{\Xi}{\Xi}$ & $\stackrel{\infty}{:}$ & 莺 & 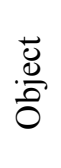 & 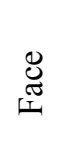 \\
\hline $\begin{array}{l}\text { Hewitt et al. }{ }^{16} \\
\text { To identify lighting } \\
\text { elements that relate to } \\
\text { the understanding of } \\
\text { lighting quality }\end{array}$ & $\begin{array}{l}\text { A bank, a drawing office, a } \\
\text { lecture hall, a laboratory } \\
\text { and a reading room } \\
\text { - Real settings }\end{array}$ & $\bullet$ & $\bullet$ & $\bullet$ & $\bullet$ & $\bullet$ & $\bullet$ & $\bullet$ & $\bullet$ \\
\hline $\begin{array}{l}\text { Kimmel and Blasdel }^{20} \\
\text { To develop scaling } \\
\text { methods for evaluating } \\
\text { subjective responses to } \\
\text { luminous environments }\end{array}$ & $\begin{array}{l}10 \text { library reading rooms } \\
\text { - Real settings } \\
\text { - Artificially lit with } \\
\text { various light levels and } \\
\text { lighting distributions }\end{array}$ & & $\bullet$ & $\bullet$ & & $\bullet$ & $\bullet$ & $\bullet$ & \\
\hline $\begin{array}{l}\text { Flynn } \text { et al. } \\
\text { To examine the effects of } \\
\text { light patterns on } \\
\text { subjective impressions } \\
\text { and users' behaviour }\end{array}$ & $\begin{array}{l}\text { A demonstration room } \\
\text { - Medium-sized conference } \\
\text { room } \\
\text { - Various combinations of } \\
\text { overhead lights, wall-lights } \\
\text { and diffuse lights }\end{array}$ & $\bullet$ & & $\bullet$ & & • & & & \\
\hline $\begin{array}{l}\text { Flynn and Spencer }{ }^{24} \\
\text { To examine the effects of } \\
\text { light colours on } \\
\text { subjective impressions }\end{array}$ & $\begin{array}{l}\text { An illumination laboratory } \\
\text { - Experimental room } \\
\text { - Various combinations of } \\
\text { overhead lights, wall-lights } \\
\text { and fluorescent lights }\end{array}$ & & $\bullet$ & $\bullet$ & & & $\bullet$ & $\bullet$ & \\
\hline $\begin{array}{l}\text { Flynn and Subisak } \\
\text { To examine the effects of } \\
\text { light settings on the } \\
\text { impression of clarity and } \\
\text { seat preferences }\end{array}$ & $\begin{array}{l}\text { An experimental room } \\
\text { - Mock-up offices of } \\
\text { different sizes } \\
\text { - Luminaire layouts with } \\
\text { different spacing ratios }\end{array}$ & • & • & $\bullet$ & & • & & & \\
\hline $\begin{array}{l}\text { Hawkes et al. } \\
\text { To examine the effects of } \\
\text { lighting distributions on } \\
\text { subjective preferences } \\
\text { and impressions }\end{array}$ & $\begin{array}{l}\text { An experimental room } \\
\text { - Mock-up windowless } \\
\text { two-person office space } \\
\text { - Various combinations of } \\
\text { recessed lights, wall-lights } \\
\text { and downlights }\end{array}$ & • & $\bullet$ & • & & & & & \\
\hline
\end{tabular}


Table 1. Continued

\begin{tabular}{|c|c|c|c|c|c|c|c|c|c|}
\hline \multirow[b]{2}{*}{ Study } & \multirow[b]{2}{*}{ Setting } & \multicolumn{8}{|c|}{ Visual focus } \\
\hline & & $\frac{\frac{0}{a}}{\frac{\pi}{2}}$ & $\frac{\dot{\delta}}{\bar{I}}$ & $\frac{\bar{\pi}}{3}$ & $\frac{\Xi}{\text { 三 }}$ & $\stackrel{\infty}{.0}$ & : & $\frac{\grave{U}}{\frac{\tilde{U}}{0}}$ & 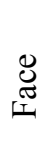 \\
\hline $\begin{array}{l}\text { Shepherd et al. }{ }^{34,35} \\
\text { To develop a model that } \\
\text { evaluates the impression } \\
\text { of gloominess }\end{array}$ & $\begin{array}{l}\text { A lighting laboratory } \\
\text { - Mock-up windowless } \\
\text { teaching space } \\
\text { - Various combinations of } \\
\text { wall-lights and downlights }\end{array}$ & $\bullet$ & $\bullet$ & $\bullet$ & & $\bullet$ & & & \\
\hline $\begin{array}{l}\text { Loe } \text { et }^{\text {al. }}{ }^{26,27} \\
\text { To examine the effects of } \\
\text { a luminous environment } \\
\text { and its lighting patterns } \\
\text { on subjective } \\
\text { assessments }\end{array}$ & $\begin{array}{l}\text { An experimental room } \\
\text { - Mock-up windowless } \\
\text { conference room } \\
\text { - Light patterns were } \\
\text { created by combinations of } \\
\text { uplighters and fluorescent } \\
\text { tubes }\end{array}$ & $\bullet$ & • & $\bullet$ & & • & $\bullet$ & & \\
\hline $\begin{array}{l}\text { Pellegrino }^{36} \\
\text { To examine the } \\
\text { relationship between } \\
\text { visual comfort and light } \\
\text { measurements }\end{array}$ & $\begin{array}{l}\text { A manager's office } \\
\text { - Real setting } \\
\text { - Various combinations of } \\
\text { louvered luminaires, } \\
\text { ceiling-mounted } \\
\text { luminaires and uplights }\end{array}$ & $\bullet$ & $\bullet$ & $\bullet$ & $\bullet$ & $\bullet$ & $\bullet$ & $\bullet$ & \\
\hline $\begin{array}{l}\text { Moore et al. }{ }^{31,32} \\
\text { To examine the effects of } \\
\text { occupant-controlled } \\
\text { lighting on light output } \\
\text { and energy consumption }\end{array}$ & $\begin{array}{l}14 \text { open-plan offices } \\
\text { - Real settings with } \\
\text { individually-controlled } \\
\text { lights } \\
\text { - Various combinations of } \\
\text { downlights, and } \\
\text { fluorescent lights }\end{array}$ & $\bullet$ & $\bullet$ & $\bullet$ & $\bullet$ & $\bullet$ & $\bullet$ & $\bullet$ & \\
\hline $\begin{array}{l}\text { Newsham et al. }{ }^{37} \\
\text { To develop models that } \\
\text { quantify the } \\
\text { psychological effects of } \\
\text { lighting distribution }\end{array}$ & $\begin{array}{l}\text { An experimental room } \\
\text { - Computer-simulated } \\
\text { images of an open-plan, } \\
\text { partitioned office } \\
\text { - Various combinations of } \\
\text { task lights and wall-lights }\end{array}$ & • & & • & & $\bullet$ & $\bullet$ & & \\
\hline $\begin{array}{l}\text { Dubois et al. }{ }^{12} \\
\text { To examine the effects of } \\
\text { window coating } \\
\text { materials on visual } \\
\text { perception }\end{array}$ & $\begin{array}{l}\text { An experimental room } \\
\text { - Scale model of an office } \\
\text { - Daylit space }\end{array}$ & $\bullet$ & $\bullet$ & $\bullet$ & & $\bullet$ & & $\bullet$ & \\
\hline
\end{tabular}


What also emerges from this review is that lighting effects of architectural interiors and workplanes have dominated the research, whereas the presence of people has received far less attention. The former generates variations in light patterns and luminance distribution $^{25}$; the latter influences the three-dimensional modelling of people and objects..$^{38}$ Both effects should be considered simultaneously because buildings are, fundamentally, designed for and occupied by people. Such disproportionate attention therefore needs to be addressed.

How best to measure the effects of occupants and objects on perceptions of a lit environment has only been sporadically examined. Some key issues clearly call for further study.

1. Researchers often study the effect of various lighting conditions (e.g. diffuse and directional lighting) on perceptions of a lit environment using a single occupanttypically a real person or a plaster model with facial features - and a matt white sphere. ${ }^{39-42}$ Measuring lighting effects using a model face is commonly reported as more suggestive than using a single generic object. ${ }^{39,42}$ It has also been observed that subjects tend to appreciate a lit environment more with directional lighting, as that creates a more dramatic effect. ${ }^{39}$ Such studies have, however, been inconclusive, as the assessments took place at a single viewing position, and thus the applicability of the findings is limited.

2. Studies were published between the 1950s and the 1980s, but not recently. No definitive conclusions can be drawn from the very few studies available. More 
recent scholarly work has only treated street lighting focusing on the relationships between obstacles, face recognition and pedestrians' needs. ${ }^{43-45}$

The effects of occupancy have, however, been rigorously considered in lighting control studies, ${ }^{17-19,46,47}$ in part because using sensors, switches and dimmers to reduce lighting energy consumption is closely associated with patterns of occupancy. ${ }^{17,19,48}$

Perhaps it is unsurprising that conducting experiments in empty spaces is more appealing among the lighting community due to the challenges and limitations imposed by more realistic contexts, but is it worthwhile to invest in transforming an empty space into an occupied one? Does using an occupied space result in distinctly different light measurements? Does using a more accurate representation of lit scenes provide useful insight for further analysis?

The need to conduct an appraisal of concert lighting for the King's College Chapel in Cambridge provided us with a unique opportunity to experiment with measurement methods in a real complex setting. As part of a research programme, we explored ways to examine light through the combination of conventional and modern methods. In this study, specifically, we tested the feasibility, effectiveness and worthiness of using dummies and objects to construct an occupied experimental scene in the chapel. 


\section{Method}

\subsection{The experimental space}

As part of a lighting appraisal for concert performances in the King's College Chapel, two field surveys of concert lighting (Figure 1) were carried out in the chapel during the winter when the days are short. This made it easier to avoid daylight disrupting the planned indoor illumination levels in the chapel. The dimensions of the chapel's performance space are 10.26 by $13.55 \mathrm{~m}$, and the total floor area is $139 \mathrm{~m}^{2}$. Given the constraints and limitations imposed by the context, the research concentrated on the three light settings described in Figure 2. One similarity among the three settings was that the peripheral lighting for the walls and the wooden screen of the chapel was identical in all of them. 
Figure 1. Layout of the experimental set-up

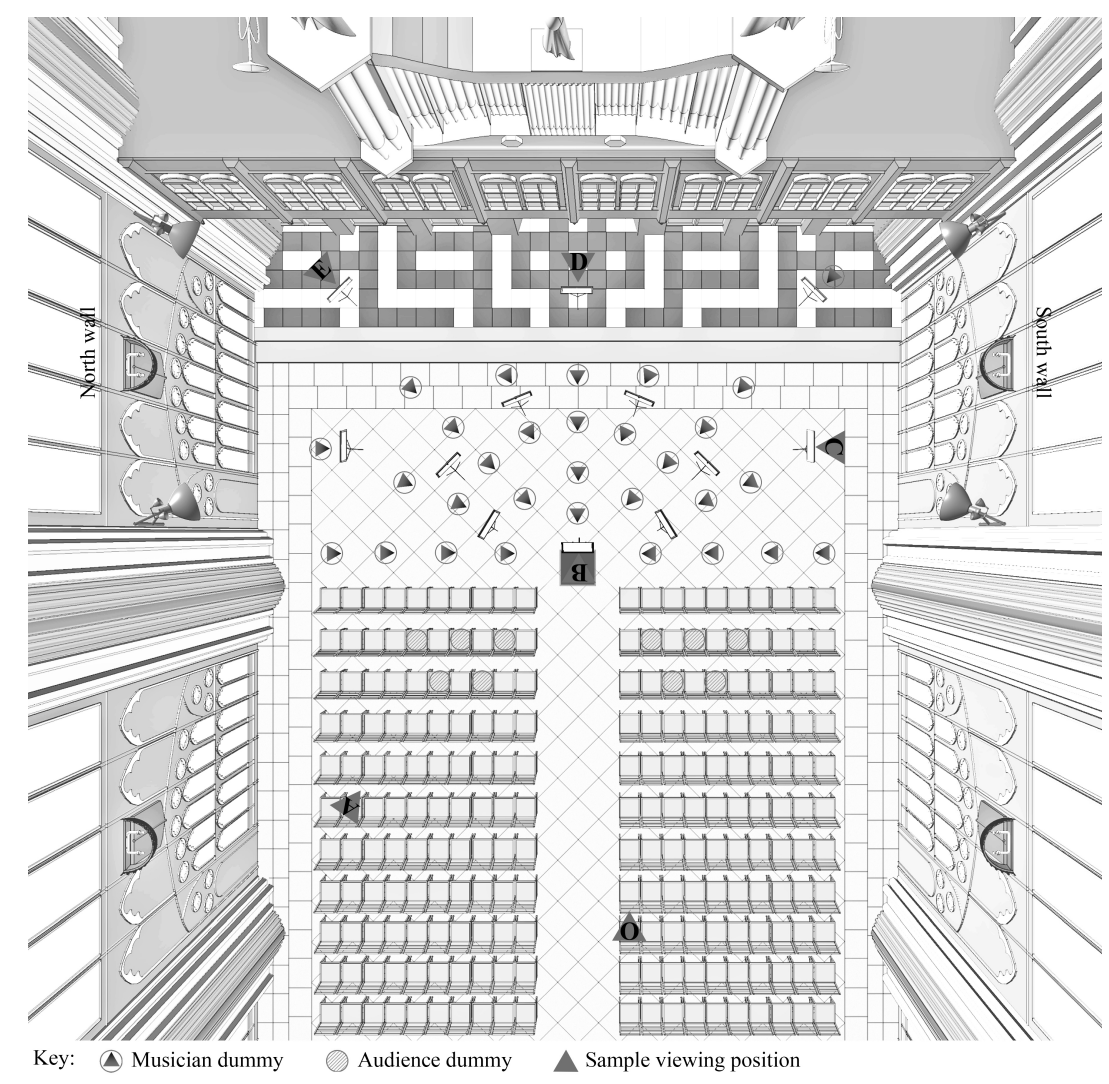

Figure 2. Lighting arrangements

(a) Rig Lighting

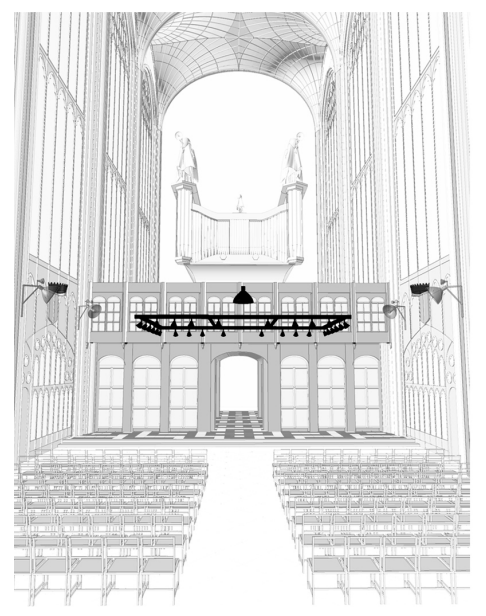

Twenty-eight Havells Sylvania Hi-Spot 95 halogen lights and a Megaman 320w energy-saving fluorescent lamp suspended at four metres above the performance area (b) Interim Lighting

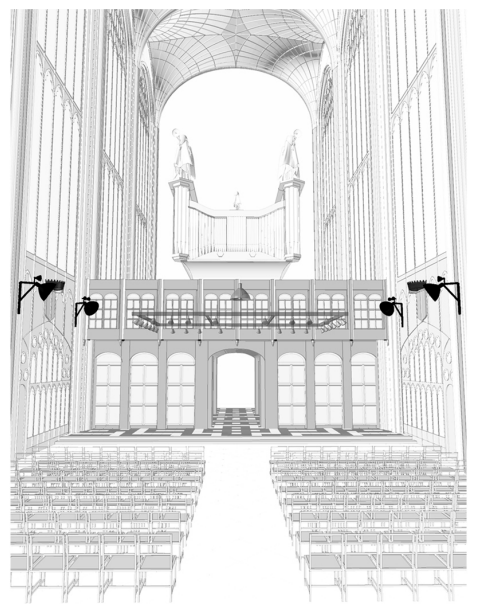

Four sets of light fixtures were mounted on the North and South walls. Each set consisted of a Megaman 320w energy-saving fluorescent lamp and two supplementary 16w Philips MasterLed spotlights. (c) All Lighting

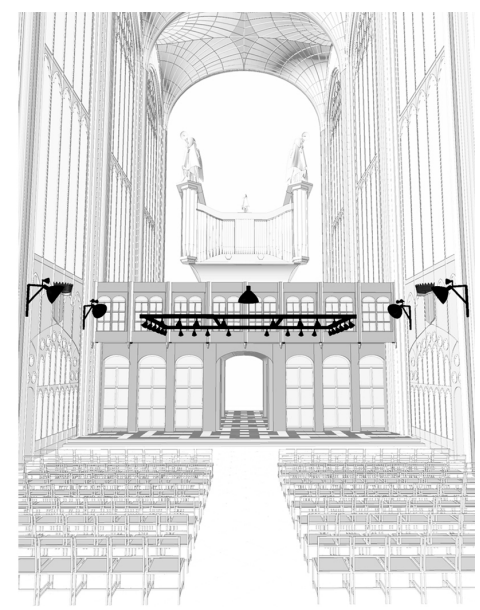

Rig Lighting + Interim Lighting 


\subsection{Sampling the illumination}

Given the complex context of the chapel, the visual field and working lighting were sampled from six different viewing positions (Figure 1): Spot O (in the audience), Spot A (in the audience), Spot B (the conductor's position), Spot C (a musician's position), Spot D (a musician's position) and Spot E (also a musician's position). This resulted in 18 visual scenarios (three light settings x six viewing positions) being studied. Because of logistical and accessibility constraints, the field measurements were made over a number of evenings. To reconstruct the visual scene for each night of testing it was necessary to ensure the exact positioning of the music stands and furniture by adhering to a predefined layout. Also, the height of the musicians' and the conductor's music stands was always adjusted to $720 \mathrm{~mm}$ and $1200 \mathrm{~mm}$ respectively, with the music stands always tilted upward at $30^{\circ}$. The measurements were made at an assumed eye level of $1240 \mathrm{~mm}$ for all of the positions except that of the conductor, Spot B, where the height was $1450 \mathrm{~mm}$. A distance of 650 $\mathrm{mm}$ from the musician's score or the viewer's programme was assumed in each measurement.

\subsection{Reconstruction of an occupied space}

A first set of measurements was made with the space unoccupied. As would be expected, the absence of occupants and objects gave the space a distinctly empty feel. Taking physical measurements and conducting experiments during rehearsals or concerts was considered to cause unacceptable distraction. Inviting musicians to help recreate a concert was considered, but it was felt that it would give rise to access and security concerns and perhaps disrupt college activities. Taken together, these limitations prompted the idea 
of using dummies to recreate a realistic visual scene. So measurements were made after transforming the empty chapel into an occupied one using dummies and objects (Figure 3).

Using dummies as a research tool is not new. Dummy heads, for example, are widely used at specific positions in concert halls in acoustics research. ${ }^{49}$ But in acoustics too some have pointed out that recordings and measurements in empty spaces may fail to yield an accurate representation of the sound effects when the same space is occupied. ${ }^{50}$ The classic work of Cuttle $e^{51}$ on the flow of light used dummies and objects to study the effects of directional lighting on appearance. Other work using dummies was, however, limited to street lighting, and the dummies were a substitute for pedestrians during visibility measurements. ${ }^{52,53}$

For fidelity, a concert environment was reconstructed in these experiments using 30 musician dummies and 10 audience dummies. Each dummy was assembled from a polystyrene head and half of a mannequin torso. Attention to detail was particularly crucial because the overall appearance of the dummies would affect the way light was reflected (Figure 4). To this end, each dummy head was carefully crafted with acrylic paint and covered with a wig (for a musician dummy) or a hat (for an audience dummy). Each dummy body was clothed in a white shirt and a black cardigan, replicating the appearance of a musician. The musician dummies were placed in the centre of the performance area and were arranged in a concentric pattern facing the conductor and audience members (Figure 1). The music stands bore two pages from a printed instrumental score. The chairs and the conductor's podium were also placed so that the final experimental scene matched as closely as possible that of a real concert with regard to light reflection and scattering. 
Figure 3. An empty performance space and an occupied performance space
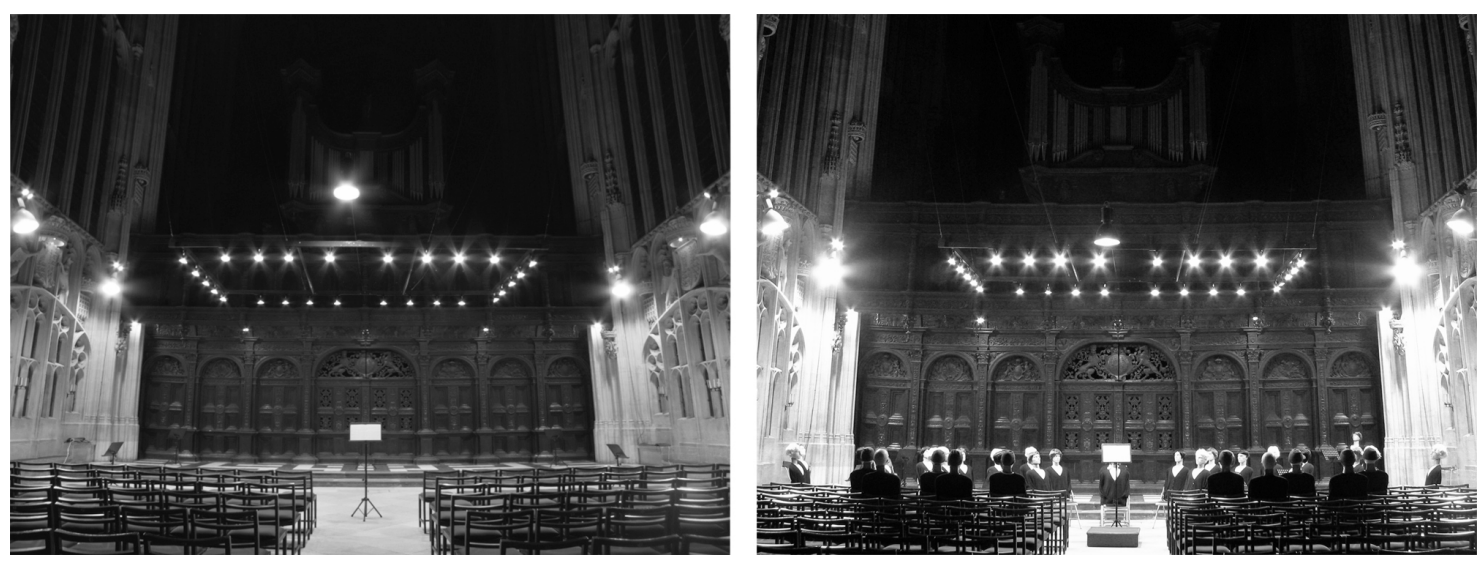

Figure 4. Musician dummies as they appeared under different light settings (From left to right: Rig Lighting, Interim Lighting and All Lighting)
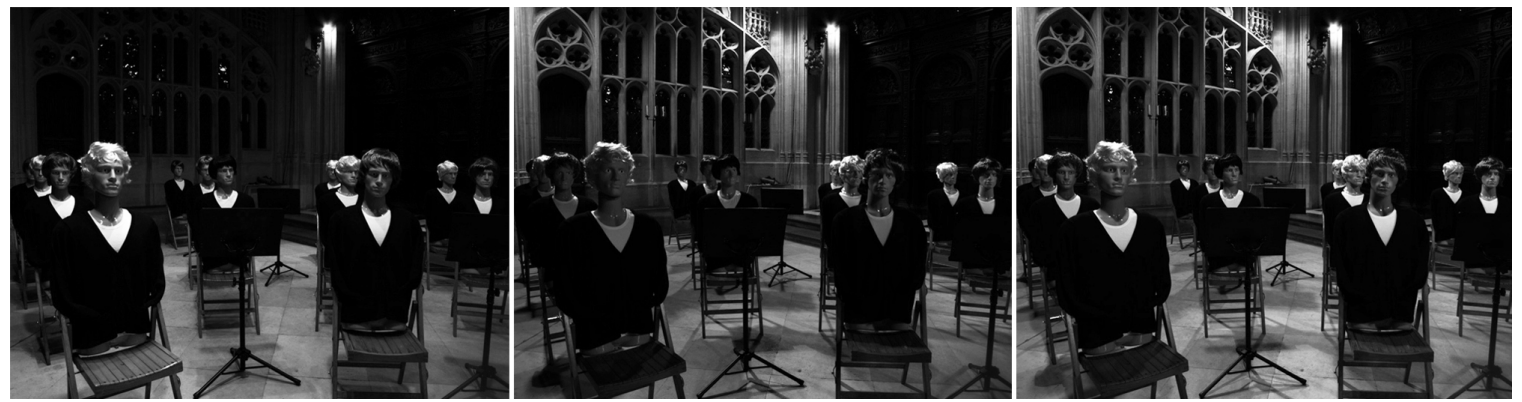

\subsection{Procedure}

The visual field was captured under the three lighting conditions with a consumerquality camera fitted with a full hemispherical fish-eye lens. The camera was mounted firmly on a tripod throughout the data acquisition process. All of the images were generated using high dynamic range (HDR) photography. Each HDR image was calibrated against physical luminance measurements taken with a Minolta LS-100 luminance meter using Radiance $^{54}$ to merge 15 raw images (4032 x 3024 pixels) of each lighting condition. The spectral response of the meter's photocell was calibrated to match the CIE relative photopic luminous efficiency, thus ensuring the photometric data extracted from the HDR images were corrected. The average error in luminance was $9.88 \%$, which is similar to the values 
reported by Inanici and Gavin, ${ }^{55}$ Inanici, ${ }^{56}$ Moeck $^{57}$ and Newsham and Arsenault. ${ }^{58}$ A set of binary masks was created to define regions of the visual field assuming binocular vision with left and right monocular fields. With reference to Ruch and Fulton's ${ }^{59}$ perimeter chart, the monocular fields each extend from $60^{\circ}$ to $90^{\circ}$. Luminous data were then extracted using the MATLAB software suite. ${ }^{60}$ The analysis of light levels in relation to the monocular and binocular fields aimed to describe how light distribution would be affected across the visual field. In addition to analysing the photometric data in relation to the structure of the visual field, a large number of variables were derived to describe the luminous scene quantitatively. For the purpose of testing our experimental methods, we adopted basic numerical descriptions, also used by other researchers, ${ }^{61,62}$ to describe the scene. Some of the most pertinent were:

$\mathrm{L}_{\text {avg }}$
$\mathrm{L}_{\text {std }}$
$\mathrm{L}_{\mathrm{var}}$
$\mathrm{LLM}_{\mathrm{avg}}$
$\mathrm{LRM}_{\mathrm{avg}}$
$\mathrm{LB}_{\mathrm{avg}}$
$\mathrm{LLM}_{\text {std }}$
$\mathrm{LRM}_{\text {std }}$
$\mathrm{LB}_{\text {std }}$
$\left(\left(\mathrm{LLM}_{\mathrm{avg}}+\mathrm{LRM}_{\mathrm{avg}}\right) / 2\right): \mathrm{LB}_{\mathrm{avg}}$
$\left(\left(\mathrm{LLM}_{\mathrm{std}}+\mathrm{LRM}_{\text {std }}\right) / 2\right): \mathrm{LB}_{\text {std }}$
$\mathrm{LLM}_{\text {avg }}: \mathrm{LRM}_{\text {avg }}$
$\mathrm{LLM}_{\text {std }}: \mathrm{LRM}_{\text {std }}$

Average luminance of a full visual field

Standard deviation of the luminance of a full visual field Variation of luminance of a full visual field

Average luminance seen through the left monocular field

Average luminance seen through the right monocular field

Average luminance seen through the binocular field Standard deviation of the luminance seen through the left monocular field

Standard deviation of the luminance seen through the right monocular field

Standard deviation of the luminance seen through the binocular field

A ratio of average luminance seen through the left and right monocular fields to average luminance seen through the binocular field

A ratio of the standard deviation of the luminance seen through the left and right monocular fields to the standard deviation of luminance seen through the binocular field

A ratio of average luminance seen through the left monocular field to that seen through the right monocular field A ratio of the standard deviation of luminance seen through the left monocular field to that seen through the right monocular field 


\section{Results and discussion}

\subsection{Luminances empty and occupied}

Figure 5 compares luminances in relation to the structure of the visual field. The graphical interpretation of the data allows a more explicit characterisation of the light distributions. Comparing the measurements describing the empty and occupied spaces, the least discrepancy was observed at Spot $\mathrm{O}$ (in the audience) while the greatest were at spots A (in the audience), B (the conductor's position) and E (a musician's position). The closer to the performance area, the greater the discrepancy in the measurements. This is unsurprising because visual fields there were more likely to be affected by light patterns and shadows cast by the dummies, furniture and music stands. Figure 5 shows that there is little difference in the variation of luminance of a full visual field ( $\mathrm{L}_{\mathrm{var}}$ ) at Spot A with the space empty or occupied. At Spot A, Lavg and Lstd were generally lower with the space occupied, but their distribution patterns followed closely that of the empty space. However, when a viewing position was in the light, as is the case of Spot $\mathrm{B}$, there was a noticeable difference observed between the empty and occupied spaces. Compared to the empty space, $\mathrm{L}_{\text {avg }}$ and $\mathrm{L}_{\text {std }}$ measured in the occupied space under Interim Lighting (i.e. peripheral wall lighting) were, respectively $76 \%$ and $92 \%$ lower in the (central) region of the binocular field than in the monocular (peripheral) fields. The pattern in the All Lighting condition (i.e. central overhead lighting with peripheral wall lighting) was similar. In fact, $\mathrm{L}_{\mathrm{var}}$ measured under Rig Lighting (i.e. central overhead lighting alone) was 95\% lower, whereas that under Interim Lighting (i.e. just peripheral wall lighting) was 30\% higher. The difference in luminances seems to be explained by the markedly reduced amount of light reflected from the floor when dummies, furniture, objects and their shadows were present. 
For the same reason, $\mathrm{L}_{\mathrm{avg}}$ measured at $\mathrm{Spot} \mathrm{E}$ was $61 \%$ to $71 \%$ lower in the right peripheral field and $\mathrm{L}_{\text {std }}$ was $80 \%$ to $98 \%$ lower, particularly when the peripheral wall lighting was included. Note, though, that Spot E was out of the light. 
Figure 5. Luminances in relation to the structure of the visual field (Left monocular field (LLMavg; LLM ${ }_{\text {std }}$ ), binocular field (LBavg; LBstd), right monocular field (LRMavg; LRM $_{\text {std }}$ ) and whole visual field (Lavg; Lstd))
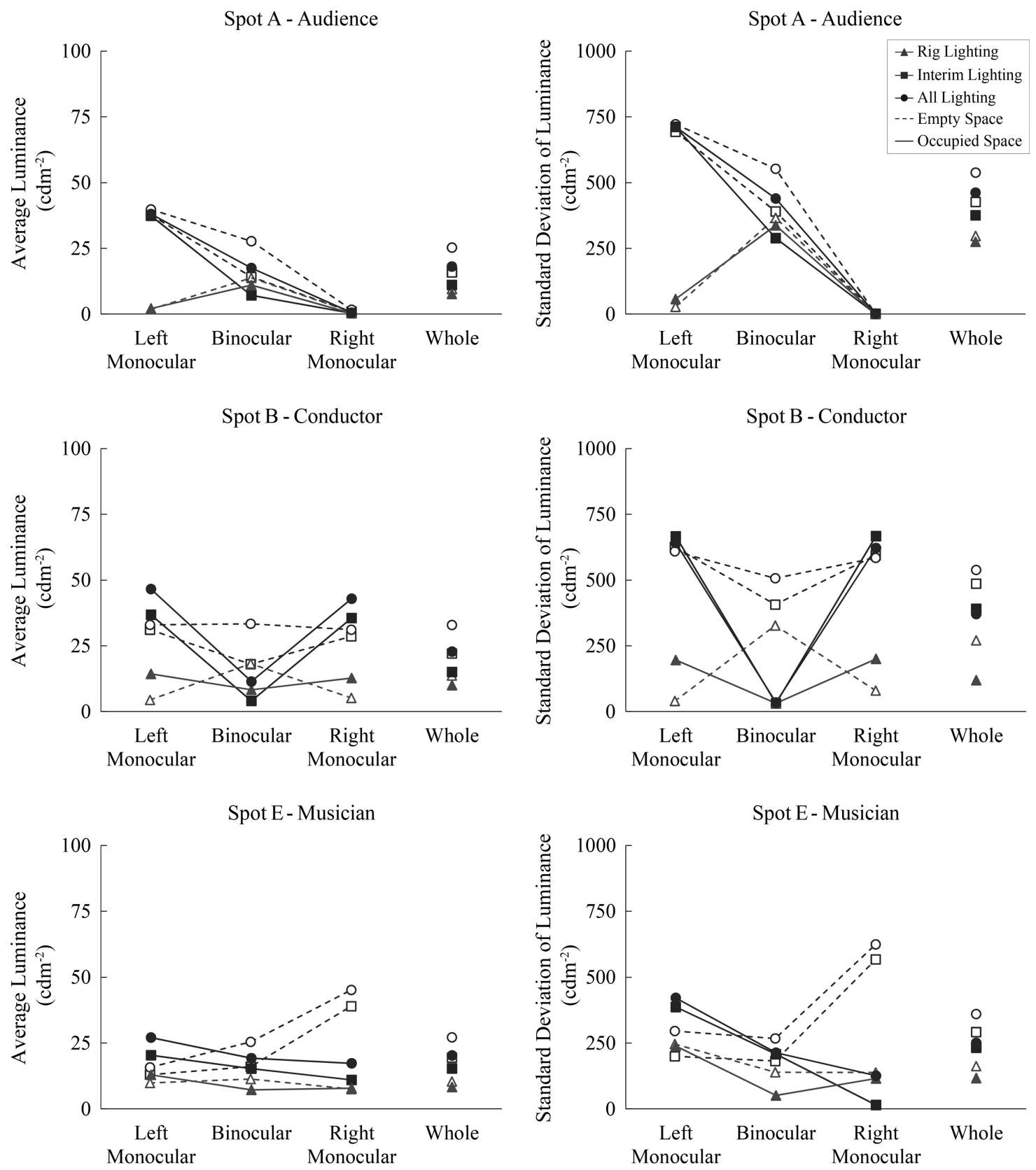


\subsection{Uniformity ratios empty and occupied}

As the plots clearly show, the tests using the occupied space also reflected differences in uniformity owing to the differences in luminances. Table 2 summarises uniformity ratios as viewed at each position in relation to the structure of the visual field.

When considering the luminances as seen through the monocular field relative to that through the binocular field, spots B (the conductor's position) and D (a musician's position) exhibited the largest differences in the ((LLMavg $\left.\left.+\mathrm{LRM}_{\text {avg }}\right) / 2\right): \mathrm{LB}_{\text {avg }}$ and ((LLM $\left.\left.M_{\text {std }}+\mathrm{LRM}_{\text {std }}\right) / 2\right): \mathrm{LB}_{\text {std }}$ ratios. The values calculated for the occupied space were 2 to 5 times higher than those for the empty space based on the average luminances, and 10 to 25 times higher based on the standard deviations of the luminances. The luminance distribution as viewed at spots B and D varied significantly with occupation. At Spot E, however, the values appear to be smaller and closer to 1.00 under Interim Lighting (i.e. peripheral wall lighting) and All Lighting (i.e. the combination of central overhead lighting and peripheral wall lighting). The luminances were more uniformly distributed across the visual fields when the chapel was occupied. 
Table 2. Empty and occupied uniformity ratios $\left(\mathrm{Ur} 1=\left(\left(\mathrm{LLM}_{\text {avg }}+\mathrm{LRM}_{\mathrm{avg}}\right) / 2\right): \mathrm{LB}_{\text {avg }} ; \mathrm{Ur} 2=\left(\left(\mathrm{LLM}_{\mathrm{std}}+\mathrm{LRM}_{\mathrm{std}}\right) / 2\right): \mathrm{LB}_{\mathrm{std}} ;\right.$ Ur3 = LLMavg:LRMavg; Ur4 = LLMstd:LRMstd)

\begin{tabular}{|c|c|c|c|c|c|c|c|c|}
\hline & \multicolumn{4}{|c|}{ Empty performance space } & \multicolumn{4}{|c|}{ Occupied performance space } \\
\hline & Ur1 & $\mathrm{Ur} 2$ & Ur3 & Ur4 & Ur1 & Ur2 & Ur3 & Ur4 \\
\hline \multicolumn{9}{|l|}{ Spot O - Audience } \\
\hline Rig Lighting & 0.09 & 0.01 & 1.00 & 0.96 & 0.08 & 0.01 & $2.10^{* *}$ & 0.79 \\
\hline Interim Lighting & 0.06 & 0.01 & 0.80 & 0.80 & 0.06 & 0.01 & $1.50^{* *}$ & 0.85 \\
\hline All Lighting & 0.06 & 0.01 & 0.88 & 0.85 & 0.08 & 0.01 & $1.00^{*}$ & $1.00^{*}$ \\
\hline \multicolumn{9}{|l|}{ Spot A - Audience } \\
\hline Rig Lighting & 0.10 & 0.04 & 2.24 & 18.62 & 0.11 & 0.09 & $7.89^{* *}$ & $125.59^{* *}$ \\
\hline Interim Lighting & 1.37 & 0.89 & 38.17 & 423.34 & $2.65^{* *}$ & 1.23 & $119.92^{* *}$ & $1761.70^{* *}$ \\
\hline All Lighting & 0.75 & 0.66 & 23.45 & 310.92 & $1.10^{*}$ & 0.81 & $71.74^{* *}$ & $1044.91^{* *}$ \\
\hline \multicolumn{9}{|c|}{ Spot B - Conductor } \\
\hline Rig Lighting & 0.62 & 0.61 & 4.25 & 4.70 & $1.64^{*}$ & $6.33^{* *}$ & $\underline{\underline{1.13}}$ & $\underline{\underline{0.98}}$ \\
\hline Interim Lighting & 1.71 & 1.51 & 1.09 & 1.06 & $8.99^{* *}$ & $21.65^{* *}$ & 1.04 & 1.00 \\
\hline All Lighting & 0.96 & 1.17 & 1.08 & 1.05 & $3.92^{*}$ & $18.32^{* *}$ & 1.09 & 1.03 \\
\hline \multicolumn{9}{|l|}{ Spot C - Musician } \\
\hline Rig Lighting & 0.48 & 0.25 & 0.70 & 0.06 & 0.45 & 0.10 & 0.80 & $0.16^{*}$ \\
\hline Interim Lighting & 0.50 & 0.20 & 0.82 & 0.10 & $\underline{0.28}$ & 0.02 & 0.75 & $0.78^{*}$ \\
\hline All Lighting & 0.46 & 0.20 & 0.85 & 0.11 & 0.43 & 0.15 & $1.00^{*}$ & $1.00^{* *}$ \\
\hline \multicolumn{9}{|l|}{ Spot D - Musician } \\
\hline Rig Lighting & 1.31 & 0.94 & 0.72 & 0.58 & $2.18^{* *}$ & $9.70^{* *}$ & 0.86 & $1.10^{* *}$ \\
\hline Interim Lighting & 4.12 & 5.57 & 0.96 & 0.86 & $7.12^{* *}$ & $79.67^{* *}$ & $\underline{0.69}$ & 0.71 \\
\hline All Lighting & 2.36 & 2.11 & 1.05 & 1.04 & $5.49^{* *}$ & $52.01^{* *}$ & $\underline{0.77}$ & $\underline{0.79}$ \\
\hline \multicolumn{9}{|l|}{ Spot E - Musician } \\
\hline Rig Lighting & 0.74 & 1.42 & 1.37 & 1.85 & $1.44^{* *}$ & $3.46^{* *}$ & $1.64^{*}$ & $2.06^{*}$ \\
\hline Interim Lighting & 1.67 & 2.18 & 0.31 & 0.34 & $\underline{1.03}$ & $\underline{\underline{0.97}}$ & $1.85^{* *}$ & $26.26^{* *}$ \\
\hline All Lighting & 1.21 & 1.76 & 0.33 & 0.46 & 1.15 & $\underline{1.28}$ & $1.57^{* *}$ & $3.34^{* *}$ \\
\hline
\end{tabular}

(*) Measurement taken from the occupied space is moderately greater than that from the empty space $\left({ }^{* *}\right)$ Measurement taken from the occupied space is considerably greater than that from the empty space (-) Measurement taken from the occupied space is moderately smaller than that from the empty space ( ) Measurement taken from the occupied space is considerably smaller than that from the empty space 
When considering the left and right monocular fields only, the calculated LLMavg:LRMavg and LLMstd:LRMstd ratios were generally higher in the occupied setting. Specifically, average luminance was 3 times higher at Spot A (in the audience) based on average luminances and 3 to 7 times higher based on the standard deviation of the luminances. At Spot E (a musician's position) it was 4 to 6 times higher based on average luminances and 7 to 80 times higher based on their standard deviation. Values closer to 1.00 indicate a more uniform distribution as seen through the left and right monocular fields. As with luminances, the effects of light patterns and shadows on uniformity must be considered.

\subsection{Additional geometrical details}

Another noteworthy aspect of using this method is that more independent variables can be created to describe various spatial aspects of a scene's luminance. For example, the size and number of light patches, the luminance difference between the background luminance and the luminance of different visual targets (e.g. faces, surfaces and objects), as well as the relative size of light and shadow patterns can all be quantified. Not only does an occupied setting give a more accurate simulation of light distribution, it also makes available a larger set of variables for further analysis. Such information allows a more detailed and complete description of a lit scene.

\section{Conclusion}

Performing experiments in an unoccupied space is a common practice in lighting research. Not only has this led to incomplete results, it has also overlooked the combined effects of facial and object modelling and occupancy on lit environments. These compromises call for much more scholarly attention. Using dummies and objects to better represent a lit 
scene is a simple yet workable solution to this fundamental methodological problem. This comparative study of the illumination in the King's College Chapel when it was empty and when it was occupied highlights a definite need for using occupied spaces in lighting studies.

The lighting type, light levels and historic context examined differentiate this study from previous ones. It also has demonstrated the effectiveness of combining conventional and modern methods to examine light in a real complex setting. It is this combination that makes this study a valuable contribution to the field of lighting research.

The levels of overall luminance measured under peripheral lighting were up to $30 \%$ higher in the occupied space. More strikingly, those measured under the combination of peripheral wall lighting and central overhead lighting appear to be up to $98 \%$ lower in the occupied space. The uniformity also differed considerably. The uniformity based on average luminances was 6 times higher than with the chapel empty, and that based on the standard deviation of luminances was 80 times greater. In addition to reducing the extent of under- and over-estimations, studying the occupied space permitted quantifying more variables describing the geometrical details of the lit scene for further analysis.

It can be argued that the way researchers isolate the changes in light patterns from other perceptually-salient visual elements (occupants and objects in this case) does not seem to provide a complete understanding of perceived luminance distribution in real contexts. Because this study involved a real (and indeed historic) environment, the reconstruction of an occupied space with dummies and objects was driven primarily by that site specific constraints. 
The following conclusions can be drawn:

- It is important to account for the presence of occupants and objects in lighting studies. Doing so will yield a more accurate and more detailed description of a lit scene which can then be exploited to compare lighting scenarios.

- Dummies are simple and inexpensive to construct, providing an effective and economical alternative to using real people. The use of dummies also makes it more convenient to reconstruct an occupied scene for additional experimental sessions.

- Dummies give more control over an experimental set-up, making it easier to acquire light measurements compared to involving real people.

Nonetheless, this method by no means yielded the exact luminance patterns and levels one would experience at a real concert. Placing more dummies in the chapel no doubt would increase the realism of the experiments. The emphasis of this paper however was not solely on the presence of occupants, and some representation of them through a simple intervention was therefore considered appropriate. The dummies used were static. In practice, changes of position among the audience members would also be assumed to affect the lighting. And future studies might use more realistic dummies with various heights, sizes and postures, or even mobile dummies. Both would help to further advance this methodology.

Notwithstanding the limitations and the fact that this study was in the nature of a proof of concept, the findings demonstrate the importance of measuring light in occupied spaces. Future studies are needed to test this approach further in different contexts with emphasis on real settings, occupied spaces, and facial and object modelling. This discussion is limited to methods and experimental set-up. Our subsequent studies will extend the discussion to 
the occupants' impressions of different light settings, as well as investigating the correlation between subjective responses and objective measures.

\section{Acknowledgements}

The authors would like to thank Cambridge King's College for granting permission to conduct the experiments in its chapel, and Dr Tom White for assisting with the experiments.

\section{Funding}

This study was supported by the Cambridge Trust, Emmanuel College and the Cambridge Department of Architecture. 


\section{References}

1. Galasiu AD, Newsham GR, Suvagau C and Sander DM. Energy saving lighting control systems for open-plan offices: a field study. LEUKOS 2007; 4: 7-29.

2. Williams A, Atkinson B, Garbesi K, Page E and Rubinstein F. Lighting controls in commercial buildings. LEUKOS 2012; 8: 161-180.

3. Veitch JA, Newham GR. Lighting quality and energy-efficiency effects on task performance, mood, health, satisfaction and comfort. Journal of the Illuminating Engineering Society 1998; 27: 107-129.

4. Veitch JA, Newsham GR, Boyce PR and Jones CC. Lighting appraisal, well-being and performance in open-plan offices: a linked mechanisms approach. Lighting Research and Technology 2008; 40: 133-151.

5. Konis K, Lee ES and Clear RD. Visual comfort analysis of innovative interior and exterior shading systems for commercial buildings using high resolution luminance images. LEUKOS 2011; 7: 167-188.

6. Borisuit A, Linhart F, Scartezzini JL and Münch M. Effects of realistic office daylighting and electric lighting conditions on visual comfort, alertness and mood. Lighting Research and Technology 2015; 47: 192-209.

7. Knight C. Field surveys of the effect of lamp spectrum on the perception of safety and comfort at night. Lighting Research and Technology 2010; 42: 313-329.

8. Yang B, Fotios S. Lighting and recognition of emotion conveyed by facial expressions. Lighting Research and Technology 2015; 47: 964-975.

9. Commission Internationale de l'Eclairage. CIE Technical Report 161: Lighting design methods for obstructed interiors. Vienna: CIE, 2004.

10. Iwata T, Hatao A, Shukuya M and Kimura K. Visual comfort in the daylit luminous environment: structural model for evaluation. Lighting Research and Technology 1994; 26: 91-97.

11. Boyce PR, Veitch JA, Newsham GR, Jones CC, Heerwagen J, Myer M and Hunter CM. Lighting quality and office work: two field simulation experiments. Lighting Research and Technology 2006; 38: 191-223.

12. Dubois MC, Cantin F and Johnsen K. The effect of coated glazing on visual perception: a pilot study using scale models. Lighting Research and Technology 2007; 39: 283-304.

13. Custers PJM, de Kort YAW, IJsselsteijn WA and de Kruiff ME. Lighting in retail environments: atmosphere perception in the real world. Lighting Research and Technology 2010; 42: 331-343. 
14. Painter B, Mardaljevic J and Fan D. Monitoring daylight provision and glare perception in office environments. In: Proceedings of W098 \& W111-Special Track 18th CIB World Building Congress, 10-13 May 2010. pp.148-160.

15. Dangol R, Islam MS, Hyvärinen M, Bhushal P, Puolakka M and Halonen L. User acceptance studies for LED office lighting: preference, naturalness and colourfulness. Lighting Research and Technology 2015; 47: 36-53.

16. Hewitt H, Kay J, Longmore J and Rowlands E. Designing for quality in lighting. Transactions of the Illuminating Engineering Society 1967; 32: 63-89.

17. Rea MS. Occupancy and light operation. Lighting Research and Technology 1987; 19: 45-49.

18. Kurian C, Aithal R, Bhat J and George V. Robust control and optimisation of energy consumption in daylight-artificial light integrated schemes. Lighting Research and Technology 2008; 40: 7-24.

19. Iversen A, Delff P, Svendsen S and Nielsen T. Simulation of annual electric lighting demand using various occupancy profiles. Lighting Research and Technology 2012; 45: 538-549.

20. Kimmel PS, Blasdel HG. Multidimensional scaling of luminous environment. Journal of the Illuminating Engineering Society 1973; 2: 113-120.

21. Strange JW, Gostt AW. Report of the Council: January 1 - December 31, 1964. Transactions of the Illuminating Engineering Society 1964; 29: 1-16.

22. Stevens WR, McDermott LH. National Illumination Committee of Great Britain: Report for the year ended September 30, 1964. Transactions of the Illuminating Engineering Society 1965; 30: 56-61.

23. Flynn JE, Spencer TJ, Martyniuk O and Hendrick C. Interim study of procedures for investigating the effect of light on impression and behavior. Journal of the Illuminating Engineering Society 1973; 3: 87-94.

24. Flynn JE, Spencer TJ. The effects of light source color on user impression and satisfaction. Journal of the Illuminating Engineering Society 1977; 6: 167-179.

25. Hawkes RJ, Loe DL and Rowlands E. IERI: a note towards the understanding of lighting quality. Journal of the Illuminating Engineering Society 1979; 8: 111-120.

26. Loe DL, Mansfield KP and Rowlands E. Appearance of lit environment and its relevance in lighting design: experimental study. Lighting Research and Technology 1994; 26: 119-133.

27. Loe DL, Mansfield KP and Rowlands E. A step in quantifying the appearance of a lit scene. Lighting Research and Technology 2000; 32: 213-222. 
28. Rothwell SE, Campbell W. The physiological basis for the sensation of gloom: quantitative and qualitative aspects. Ophthalmic and Physiological Optics 1987; 7: 161163.

29. Perry MJ, Campbell FW and Rothwell SE. A physiological phenomenon design and its implications for lighting design. Lighting Research and Technology 1987; 19: 1-5.

30. Moore T, Carter DJ and Slater AI. User attitudes toward occupant controlled office lighting. Lighting Research and Technology 2002; 34: 207-219.

31. Moore T, Carter DJ and Slater AI. A field study of occupant controlled lighting in offices. Lighting Research and Technology 2002; 34: 191-205.

32. Moore T, Carter DJ and Slater AI. A qualitative study of occupant controlled of office lighting. Lighting Research and Technology 2003; 35: 297-317.

33. Flynn JE, Subisak GJ. A procedure for qualitative study of light level variations and system performance. Journal of the Illuminating Engineering Society 1978; 8: 28-35.

34. Shepherd AJ, Julian WG and Purcell AT. Gloom as a psychophysical phenomenon. Lighting Research and Technology 1989; 21: 89-97.

35. Shepherd AJ, Julian WG and Purcell AT. Measuring appearance: Parameters indicated from gloom studies. Lighting Research and Technology 1992; 24: 203-214.

36. Pellegrino A. Assessment of artificial lighting parameters in a visual comfort perspective. Lighting Research and Technology 1999; 31: 107-115.

37. Newsham GR, Richardson C, Blanchet $\mathrm{C}$ and Veitch JA. Lighting quality research using rendered images of offices. Lighting Research and Technology 2005; 37: 93-115.

38. Loe DL, Rowlands E. The art and science of lighting: a strategy for lighting design. Lighting Research and Technology 1996; 28: 154-164.

39. Hewitt H, Bridgers DJ and Simons RH. Lighting and the Environment: some Studies in Appraisal and Design. Transactions of the Illuminating Engineering Society 1965; 30: 91-116.

40. Fischer D. The European approach to the integration of lighting and airconditioning. Lighting Research and Technology 1970; 2: 150-163.

41. Aldworth RC, Bridgers DJ. Design for variety in lighting. Lighting Research and Technology 1971; 3: 8-23.

42. Bean AR. Lighting of occupants and objects within an interior. Lighting Research and Technology 1978; 10: 146-149. 
43. Dong $\mathrm{M}$, Fotios $\mathrm{S}$ and Lin $\mathrm{Y}$. The influence of luminance, observation duration and procedure on the recognition of pedestrians' faces. Lighting Research and Technology 2015; 47: 693-704.

44. Fotios S, Castleton $\mathrm{H}$, Cheal $\mathrm{C}$ and Yang $\mathrm{B}$. Investigating the chromatic contribution to recognition of facial expression. Lighting Research and Technology 2017; 49: 243-258.

45. Uttley J, Fotios S and Cheal C. Effect of illuminance and spectrum on peripheral obstacle detection by pedestrians. Lighting Research and Technology 2017; 49: 211-227.

46. Escuyer S, Fontoynont M. Lighting controls: a field study of office workers' reactions. Lighting Research and Technology 2001; 33: 77-94.

47. Chiogna M, Mahdavi A, Albatici R and Frattari A. Energy efficiency of alternative lighting control systems. Lighting Research and Technology 2012; 44: 397-415.

48. Yilmaz FS, Ticleanu C, Howlett G, King S and Littlefair PJ. People-friendly lighting controls - user performance and feedback on different interfaces. Lighting Research and Technology 2016; 48: 449-472.

49. Barron M. Auditorium Acoustics and Architectural Design. London: E\&FN Spon, 1993.

50. Barron M, Lee LJ. Energy relations in concert auditoriums I. Journal of the Acoustical Society of America 1988; 84: 618-628.

51. Cuttle C. Lighting patterns and the flow of light. Lighting Research and Technology 1971; 3: 171-189.

52. Hills BL. Visibility under night driving conditions: Part 2 - Field measurements using disc obstacles and a pedestrian dummy. Lighting Research and Technology 1975; 7: 251-258.

53. Brémond R, Bodard V, Dumont E and Nouailles-Mayeur A. Target visibility level and detection distance on a driving simulator. Lighting Research and Technology 2013; 45: 76-89.

54. Ward G. Rendering with Radiance: The Art and Science of Lighting Visualization. San Francisco: Morgan Kaufmann, 1998.

55. Inanici MN, Galvin J. Evaluation of High Dynamic Range Photography as a Luminance Mapping Technique. Berkeley, CA: Lawrence Berkeley National Laboratory, 2004; pp.1-28.

56. Inanici MN. Per-pixel lighting data analysis. Berkeley, CA: Lawrence Berkeley National Laboratory, 2005; pp.1-29. 
57. Moeck M. Accuracy of luminance maps obtained from high dynamic range images. LEUKOS 2007; 4: 99-112.

58. Newsham GR, Arsenault C. A camera as a sensor for lighting and shading control. Lighting Research and Technology 2009; 41: 143-163.

59. Ruch TC, Fulton JF. Medical Physiology and Biophysics, 18th Edition. Philadelphia: W.B. Saunders, 1960; 453.

60. MathWorks. MATLAB: The Language of Technical Computing. Getting Started with MATLAB. Version 7. Natick, MA: MathWorks, 2005.

61. Moore T, Graves H, Perry MJ and Carter DJ. Approximate field measurement of surface luminance using a digital camera. Lighting Research and Technology 2000; 32: 111.

62. van den Wymelenberg K, Inanici MN. A critical investigation of common lighting design metrics for predicting human visual comfort in offices with daylight. LEUKOS 2014; 10: 145-164. 